\title{
A atualidade De John Dewey para a educação: mais arte, não menos
}

\author{
Marcus Vinicius da Cunha (USP)
}

\begin{abstract}
RESUMO
Este trabalho busca mostrar que John Dewey oferece valiosa contribuição para o desenvolvimento de reflexões sobre os problemas educacionais dos dias de hoje. Para cumprir esse objetivo, o trabalho desenvolve um estudo sobre o livro Arte como experiência de Dewey, com o intuito de discutir o vínculo estabelecido pelo autor entre os dois conceitos que formam o título - arte e experiência. Os resultados desse estudo são transportados para a educação - assunto não focalizado no referido livro - considerando o cenário educacional atual. A metodologia utilizada é a análise retórica, em conformidade com os trabalhos do Grupo de Pesquisa Retórica e Argumentação na Pedagogia (USP/CNPq), cujos fundamentos encontram-se na obra de Aristóteles, em especial nos Tópicos e na Retórica, segundo a interpretação feita por Chaïm Perelman e outros integrantes do movimento contemporâneo de revisão da filosofia Aristotélica. O trabalho conclui que a transposição dos conceitos estéticos de Dewey para a educação traz várias contribuições aos educadores, apoiando medidas inovadoras, como o uso das artes na escola e a criação de novos métodos para o ensino da arte, e também oferecendo inspiração para transformar a educação em uma experiência gratificante e humanizadora. Tais contribuições, no entanto, devem ser confrontadas com a radicalidade política que está presente nas análises feitas por Dewey sobre a cultura contemporânea.
\end{abstract}

PALAVRAS CHAVES: John Dewey. Educação Contemporânea. Aristóteles. Análise Retórica.

\section{ABSTRACT}

This work seeks to show that John Dewey offers valuable contribution to think on educational problems of today. To fulfill this goal, the work studies Dewey's Art as experience in order to discuss the link established by the author between the two concepts that form the title of the book art and experience. The results of the study are transported to education subject not focused in that book - considering the educational scenery of today. The methodology is the rhetorical analysis, in accordance with the works of the Research Group Rhetoric and Argumentation in Pedagogy (USP/CNPq), whose bases are in Aristotle, especially in Topics and Rhetoric, according to the interpretation made by Chaïm Perelman and other researchers linked to the contemporary movement that promotes the revision of Aristotelian philosophy. The conclusions of the work emphasize that the transposition of Dewey's aesthetic to education brings several contributions to educators, supporting innovative measures, such as the use of the arts in teaching and the creation of new methods for teaching art, and also offering inspiration to transform education in a rewarding and humanizing experience. Such contributions should be however confronted with political radicalism that is present in the exam made by Dewey about contemporary culture.

KEYWORDS: John Dewey. Contemporary Education. Aristotle. Rhetorical Analysis. 


\section{Introdução}

Considero haver basicamente três abordagens metodológicas que viabilizam o estudo e a compreensão de uma filosofia. Cada qual possui objetivos distintos, porém complementares.

A primeira abordagem consiste em examinar as concepções de um filósofo internamente, no limite estrito de seus textos e de seu contexto histórico. Nesse tipo de estudo, buscamos interpretar os principais enunciados do autor, evidenciando a relação mútua entre eles; ou, quando for o caso, denunciando a incoerência entre suas ideias; ou, ainda, dependendo da situação, descrevendo o progresso de suas teses no decorrer do tempo. Feito isso, é possível ir além, dentro dessa mesma abordagem, e analisar as relações do filósofo em questão com outros pensadores, tendo por meta identificar semelhanças e divergências entre eles.

A segunda abordagem, igualmente útil para compreender uma filosofia, não prescinde da primeira, mas se alimenta dela, consistindo em testar as concepções do filósofo em campo alheio ao de suas preocupações originais, e também em outro tempo, distante daquele que lhe serviu de berço. Essa operação auxilia no entendimento das formulações do pensador em estudo, servindo também para ampliar nosso campo de visão acerca das consequências de suas ideias.

Há alguns anos eu venho estudando John Dewey por meio da primeira abordagem, situando tanto as suas ideias filosóficas quando as suas teses educacionais na época em que foram produzidas, e também discutindo eventuais conexões entre as concepções deweyanas e as de outros autores. Mas tenho grande interesse também na segunda abordagem, cativado pelo desafio de transportar Dewey para a atualidade, por considerar que as 
filosofias são instrumentos que devemos colocar a serviço do enfrentamento de problemas concretos (ver, por exemplo, Cunha, 1994; Cunha 2001; Pimenta de Araújo e Cunha, 2011; Andrade e Cunha, 2012).

No presente texto, procurarei mostrar que John Dewey oferece valiosa contribuição para refletirmos sobre os problemas da educação nos dias de hoje. Pretendo desenvolver o assunto por meio de uma estratégia que se vale da primeira abordagem, tomando como ponto de partida uma reflexão em torno do livro Arte como experiência de Dewey, no qual a educação não é mencionada, a não ser em algumas poucas passagens; em seguida, procurarei associar o conteúdo do livro a temáticas educacionais, considerando o cenário contemporâneo.

Ao utilizar as duas primeiras abordagens, introduzirei a terceira forma de estudo que considero especialmente valiosa para o exame de textos filosóficos. Trata-se da análise retórica, recurso teórico-metodológico que vimos adotando no Grupo de Pesquisa Retórica e Argumentação na Pedagogia, com fundamento em obras de Aristóteles, segundo a interpretação contemporânea feita por Chaïm Perelman (ver Perelman, 1982; Perelman e Olbrechts-Tyteca, 1996). Esse teórico contribuiu para a reabilitação da retórica e da dialética no âmbito da filosofia aristoteleciana, integrando o movimento que, a partir da primeira metade do século XX, conferiu destaque aos Tópicos e à Retórica e situou os Analíticos em seu devido lugar, como parte relevante, mas apenas parte do ferramental necessário ao exame de argumentos (ver Berti, 1997).

A análise retórica, conforme a vimos desenvolvendo em nosso Grupo de Pesquisa, visa identificar as estratégias argumentativas utilizadas pelo autor de um texto para persuadir seus leitores - termos que, por analogia com a situação retórica da Grécia clássica, denominamos 
respectivamente orador e auditório. A relação entre autor/orador e leitores/auditório é fundamental em qualquer manifestação pública que tenha por objetivo estabelecer disposições para a ação, o que se faz mobilizando tanto os componentes intelectuais quanto os emocionais daqueles que se apresentam como destinatários de um discurso (ver Cunha, 2010) .

Essa abordagem teórico-metodológica não tem por objetivo emitir juízos de valor sobre as proposições contidas em um texto ou sobre as supostas intenções conscientes ou inconscientes de um autor, mas compreender as articulações discursivas que respondem pela efetividade de discursos que visam comunicar problemas e apresentar soluções em determinada área de conhecimento, particularmente naquelas que envolvem ações práticas, como é o caso da educação. Por esse motivo, vemos a retórica como estreitamente associada à vida coletiva, - que coloca em primeiro plano o caráter ético da arte de argumentar.

\section{Um livro quase ignorado}

O livro Arte como experiência de John Dewey foi publicado em 1934, quando os principais textos do filósofo já não versavam sobre a educação como tema principal. Sua grande obra educacional é Democracia e educação, livro de 1916 que foi precedido por outros trabalhos também muito importantes para definir o pensamento deweyano nessa área. Por exemplo, os ensaios "Meu credo pedagógico" (1897), "A criança e o currículo" (1902) e "Interesse e esforço em educação" (1913); e os livros A escola e a sociedade (1899) e Como pensamos (1910).

Todos esses escritos descendem, de certo modo, da Escola Laboratório, a inovadora experiência de ensino implantada e 
dirigida por Dewey na Universidade de Chicago, onde ele trabalhou de 1894 a 1904 (ver Moreira, 2002; Valdemarin, 2010). Dewey voltou a discorrer sobre temáticas educacionais em 1938, vinte e dois anos depois de Democracia e educação, no livro Experiência e educação, talvez o último trabalho relevante de sua autoria nesse campo.

Essa cronologia sugere que, depois de 1916, a atenção de Dewey voltou-se prioritariamente para a filosofia, como se pode notar pelo conteúdo de seus livros publicados desde então. Dentre outros títulos, menciono Ensaios em lógica experimental (1916), Reconstrução em filosofia (1920), Natureza humana e conduta (1922), Experiência e natureza (1925), A busca da certeza (1929), Ética (1932), Lógica: teoria da investigação (1938) e Teoria da valoração (1939) .

O livro Arte como experiência enquadra-se nesse registro cronológico e intelectual: Não é um trabalho sobre educação, mas sobre estética; discorre sobre teorias da arte e propõe certo entendimento sobre a produção e a fruição de obras artísticas. Embora não explicite nenhuma proposta sobre o ensino da arte nem sobre a presença da arte no ensino, essa obra teve importante participação no ingresso da arte-educação no Brasil, o que se deu por intermédio dos estudos de Ana Mae Barbosa.

O livro de Barbosa chamado Recorte e colagem, cujo subtítulo é "influências de John Dewey no ensino da arte no Brasil", foi publicado em 1982, sendo derivado de seu doutorado, concluído alguns anos antes na Universidade de Boston, nos Estados Unidos. Com o acréscimo de dois capítulos, - mesmo livro foi publicado novamente em 2001, então com o título John Dewey e o ensino da arte no Brasil (ver Barbosa, 1982; Barbosa, 2002). Nesse texto, Barbosa (idem, p. 45) afirma que as reflexões de Dewey sobre arte podem ser 
organizadas em três fases: A primeira encontra-se no livro A escola e a sociedade; a segunda, em Democracia e educação; e a terceira em Arte como experiência.

Ao historiar o intercâmbio entre arte e educação no Brasil, a autora discute três importantes reformas do ensino articuladas na época áurea do escolanovismo: A Reforma Fernando de Azevedo no Distrito Federal, a Reforma Francisco Campos em Minas Gerais e a Reforma Carneiro Leão em Pernambuco, todas instituídas em 1927. Barbosa (1982, p. 101) observa que os responsáveis pelas inovações introduzidas por essas reformas "não tiveram acesso aos conceitos mais elaborados de Dewey sobre experiência estética e artística", os quais se encontram em Arte como experiência. Não tiveram acesso, evidentemente, porque o referido livro foi publicado somente na década seguinte à atuação dos reformistas.

Em trabalho mais recente, Barbosa (2003) afirma que iniciativas condizentes com os conceitos deweyanos mais elaborados surgiram após o término do Estado Novo, quando se buscou na arte um meio de "liberação emocional", com o objetivo de favorecer a "expressão da criança", para que ela se manifestasse com liberdade "sem interferência do adulto".

Creio que Ana Mae Barbosa tenha sido pioneira não só no estudo da arte-educação no Brasil como também na reintrodução de John Dewey em nosso meio acadêmico, uma vez que seu livro foi publicado numa época em que a filosofia deweyana ainda era tão subvalorizada quanto subestudada, juntamente com as ideias de todos os escolanovistas brasileiros e estrangeiros submetidos às objeções disseminadas por certa visão marxista. Dewey e os escolanovistas - em especial, os deweyanos - eram então chamados pejorativamente de "liberais", defensores de uma escola elitista, burguesa, contrária aos interesses das massas. Por ser americano, Dewey era ainda associado ao 


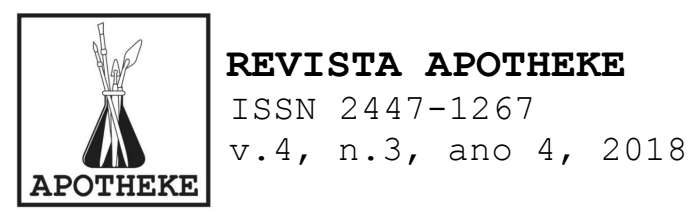

malfadado american way of life, bem como à política imperialista exercida pelos Estados Unidos sobre a América Latina (ver Cunha e Garcia, 2011; Souza, 2011).

Mesmo em seu país, aliás, como informa Barbosa (2002, p. 14), no início dos anos de 1980 Dewey ocupava espaço pouco condizente com a notável projeção que obtivera anteriormente, e só então começava a ser redescoberto, depois de praticamente duas décadas de "recessão". Um exemplo da precariedade daquele cenário é o fato de a coleção das obras completas do filósofo, organizada por Jo Ann Boydston com subsídios da Southern University, hoje com 37 volumes, tinha editado somente os 5 primeiros naquela época.

Se minha apreciação acerca do pioneirismo de Barbosa estiver correta, torna-se curioso observar que o ressurgimento de Dewey no Brasil, na década de 1980, tenha ocorrido por intermédio de uma discussão em torno das concepções deweyanas relativas à arte, em especial contidas no livro Arte como experiência. É curioso porque, segundo avalio, esse livro exerceu pouca influência na educação depois de Ana Mae Barbosa, permanecendo como referência de fundo dos arteeducadores, sem que houvesse o desenvolvimento de estudos sistemáticos sobre seu conteúdo. Na ocasião em que Ana Mae elaborou sua tese de doutorado, a situação não era muito diferente entre os defensores da arte-educação, ao que parece, pois em seu livro a autora informa que Arte como experiência era então "completamente ignorado" naquele meio intelectual (Barbosa, 1982, p. 56).

\section{A unificação de noções}

A leitura que faço de Arte como experiência não tem o intuito de rever os estudos concernentes às contribuições de Dewey para o ensino da arte ou para a inserção das artes no 
ensino, mas de colocar em primeiro plano a concepção do filósofo sobre a produção e a fruição de obras artísticas, como é o seu objetivo principal. No prefácio do livro, Dewey (2010, p. 57) informa que a obra resultou de dez conferências por ele proferidas em 1931 na Universidade de Harvard sobre filosofia da arte. O primeiro capítulo projeta a intenção de debater o isolamento em que se encontram, de um lado, os produtos artísticos, "as formas refinadas e intensificadas de experiência que são as obras de arte e, de outro, os eventos, atos e sofrimentos do cotidiano universalmente reconhecidos como constitutivos da experiência" (idem, p. 60).

Uma bela analogia nos auxilia a compreender a intenção de Dewey:

\footnotetext{
Os picos das montanhas não flutuam no ar sem sustentação, tampouco apenas se apoiam na terra. Eles são a terra, em uma de suas operações manifestas. Cabe aos que se interessam pela teoria da terra - geógrafos e geólogos - evidenciar esse fato em suas várias implicações. O teórico que deseja lidar filosoficamente com as belas-artes tem uma tarefa semelhante a realizar. (Dewey, 2010, p. 60)
}

Dewey pretende mostrar que o objeto artístico e a experiência que o gerou são uma coisa só, não coisas distintas, assim como a terra e os picos das montanhas. A estratégia discursiva empregada visa defender a existência de um fator comum vinculando dois elementos aparentemente apartados. No âmbito das ciências da terra, esse fator é a própria terra, que abarca todos os termos em exame; na esfera das artes, são as condições sociais, que envolvem tanto a ação de produzir quanto o agente e o produto; e não só, pois envolvem também aqueles que desfrutam o objeto produzido.

Para firmar sua tese, Dewey (2010, p. 61) emprega o recurso da ilustração, lembrando uma obra considerada patrimônio artístico da humanidade. Para "teorizar sobre a 


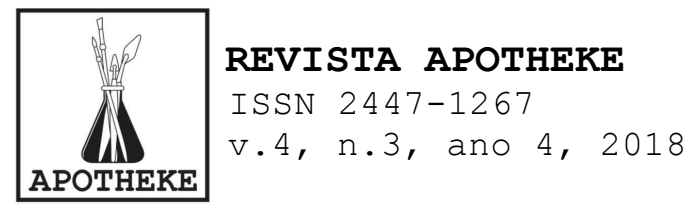

experiência estética encarnada no Partenon", diz o autor, é preciso "descobrir, em pensamento, o que aquelas pessoas em cuja vida o templo entrou, como criadoras e como as que se compraziam com ele, tinham em comum com as pessoas de nossas próprias casas e ruas".

A experiência estética - integrando produtor, produto e destinatário - não se esgota nos objetos a que se convencionou dar o nome de obras de arte e que se encontram usualmente expostos em museus. Dewey (2010, p. 62) explica que as "origens da arte na experiência humana" são devidamente compreendidas por quem perceber como "a graça tensa do jogador de bola contagia a multidão de espectadores; por quem notar o deleite da dona de casa que cuida de suas plantas e o interesse atento com que seu marido cuida do pedaço de jardim em frente à casa; por quem perceber o prazer do espectador ao remexer a lenha que arde na lareira e ao observar as chamas dardejantes e as brasas que se desfazem".

Nessa passagem, Dewey alude a cenas do cotidiano para evidenciar a qualidade que transforma atividades corriqueiras em atividades artísticas; a mesma qualidade que Coleridge vê no leitor de poesia e que podemos enxergar naqueles que "ficam alegremente absortos em suas atividades mentais e corporais": Todos se deixam envolver "não pelo desejo irrequieto de chegar à solução final, mas pela atividade prazerosa do percurso em si" (Dewey, 2010, p. 62).

O filósofo opera aqui um recurso que, no vocabulário da análise retórica, denominamos dissociação de noções. Duas noções são primeiramente colocadas em oposição, sendo em seguida hierarquizadas, atribuindo-se a uma delas predominância valorativa sobre a outra. Nos casos mencionados por Dewey, desfrutar o prazer do percurso tem mais valor do que alcançar a solução final. Trata-se de uma analogia 


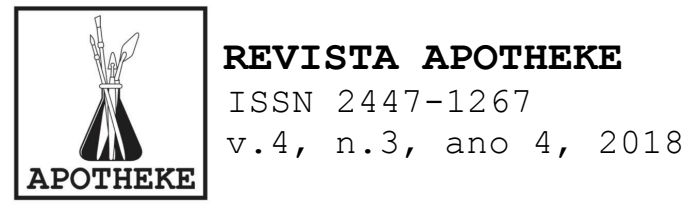

pedestre, se pudermos ver a solução final como o resultado de uma caminhada, uma trajetória que, de tão agradável, torna-se mais interessante do que chegar a seu término.

Esse raciocínio privilegia o prazer sentido no processo de realizar alguma coisa, posicionando a arte no terreno das ocorrências imprevisíveis, submetidas somente às circunstâncias do fazer. É evidente, no entanto, que no discurso deweyano esse prazer não exclui a satisfação ocasionada pela conclusão do processo. Caso contrário, não haveria integração entre o produtor e o objeto produzido. Do ponto de vista retórico, o que se observa na argumentação de Dewey é uma constante busca pela unificação de noções que, mantidas em isolamento, ocasionam dualismos que impedem a visão do todo.

Esse é também o procedimento discursivo utilizado pelo filósofo em relação aos termos arte e experiência. Dewey (2010, p. 506) sustenta que a arte é "a mais direta e completa manifestação que existe da experiência como experiência". A associação entre as duas noções permite conciliar outras noções igualmente isoladas:

\footnotetext{
(...) a realidade e a possibilidade ou idealidade, o novo e o velho, o material objetivo e a resposta pessoal, o individual e o universal, a superfície e o fundo, o sensível e o significado, tudo se integra em uma experiência em que todos se transfiguram, em relação à significação que lhes é própria quando isolados na reflexão. (Dewey, 2010, p. 506-507)
}

\section{A comunicação e as artes argumentativas}

A tese central de Arte como experiência defende o vínculo indissolúvel entre o produtor, o produto e aqueles a quem o produto se destina. Essa conexão é estabelecida pelo conceito de experiência, termo que não se reduz a vivências do indivíduo isolado. Dewey (2010, p. 83-84) explica que a 
experiência, "na medida em que é experiência", não significa "encerrar-se em sentimentos e sensações privados", mas manter "uma troca ativa e alerta com o mundo; em seu auge, significa uma interpenetração completa entre o eu e o mundo dos objetos e acontecimentos". Como "realização de um organismo em suas lutas e conquistas em um mundo de coisas", a experiência é "a arte em estado germinal", pois traduz "a promessa da percepção prazerosa que é a experiência estética".

Opondo-se às correntes psicológicas que promovem o isolamento entre o indivíduo e o ambiente, no que se incluem os demais indivíduos que integram o meio social, Dewey sustenta que os desejos e as crenças individuais, como também os conteúdos do pensamento, advêm daqueles com quem convivemos.

A expressão da experiência é pública e comunicativa porque as experiências transmitidas são como são graças às experiências dos vivos e mortos que as moldaram. Não é preciso que a comunicação faça parte da intenção deliberada do artista, embora ele nunca possa escapar da ideia de uma plateia potencial. Mas a função e a consequência da intenção consistem em realizar comunicação, e não por um acidente externo, mas a partir da natureza que ele compartilha com os outros. (Dewey, 2010, p. 466)

Esse raciocínio exprime uma reflexão sobre o fenômeno comunicacional, o que permite aproximar Dewey das artes de argumentar, as quais também envolvem dois agentes, um que emite a mensagem e um que a recebe, ambos igualmente relevantes no desenvolvimento de uma prática dotada de marcante significado cívico. Dewey (2010, p. 213) afirma que "o artista trabalha para criar uma plateia com a qual efetivamente se comunique", o que assemelha a função da obra artística à função assumida pelo discurso retórico, prática de 


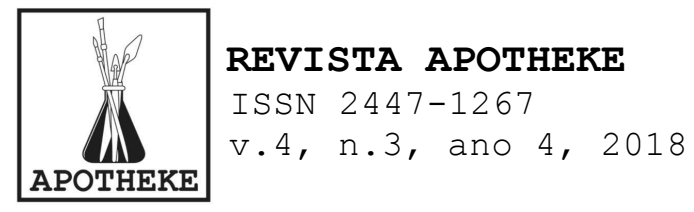

importância ímpar na polis grega. Considerando o ambiente degradado que caracteriza a sociedade contemporânea, Dewey diz que "as obras de arte são os únicos meios de comunicação completa e desobstruída entre os homens"; são os únicos meios "passíveis de ocorrer em um mundo cheio de abismos e muralhas que restringem a comunhão da experiência".

$\mathrm{Na}$ célebre frase com que Dewey (1959, p. 93) define democracia, a comunicação ocupa posição central, juntamente com o conceito de cooperação: "Uma democracia é mais do que uma forma de governo; é, primacialmente, uma forma de vida associada, de experiência conjunta e mutuamente comunicada". Viver de maneira democrática, portanto, implica não somente cooperar e desenvolver experiências conjuntamente, mas também, e principalmente, manter aberto o diálogo acerca do que é vivenciado individual e coletivamente.

As obras de arte desempenham papel semelhante ao que é assumido pelo discurso persuasivo, pois permitem, segundo Dewey (2010, p. 427), o compartilhamento vívido e profundo de "significados para os quais éramos surdos, ou para os quais tínhamos apenas o ouvido que permite que o que é dito passe em trânsito para a ação manifesta". Na concepção deweyana de comunicação, a arte não se esgota no deleite individual do artista porque que comunicar é "o processo de criar uma participação, de tornar comum o que era isolado e singular, e parte do milagre que ele realiza é que, ao ser comunicada, a transmissão do sentido dá corpo e definição à experiência, tanto de quem enuncia quanto daqueles que escutam".

Como se pode notar nessa passagem, o filósofo constrói uma analogia entre a função da arte e as operações do ouvido, órgão que, funcionando adequadamente, torna possível a comunicação. Essa analogia merece atenção especial, uma vez que o livro Arte como experiência utiliza principalmente 
esculturas e pinturas para ilustrar suas teses; seria então razoável que, para explicar as funções comunicacionais da arte, o autor preferisse indicar o sentido da visão. Ao optar pela audição, Dewey nos conduz aos domínios da oralidade, sendo inevitável lembrar que, desde a origem da civilização ocidental, as artes da retórica e da dialética são classificadas entre as manifestações cívicas mais importantes dessa forma de comunicação.

Aristóteles (Retórica, I, 135a1) assemelha a retórica à dialética, dizendo que a primeira é antístrofos da segunda, o que, segundo os tradutores, pode significar outra face, análogo ou, ainda, contrapartida (ver Reboul, 2004, p. 34-35). A retórica se faz por meio de um discurso pronunciado perante um auditório silencioso reunido em uma assembleia, um tribunal ou uma cerimônia festiva, visando à persuasão; a dialética é um diálogo praticado entre interlocutores que buscam definir conjuntamente algum conceito sobre o qual pairam dúvidas. O que aproxima as duas práticas é o fato de ambas transcorrem no terreno do verossímil, não no campo do necessário, adotando, como ponto de partida, noções comuns, não verdades científicas, ou seja, noções assumidas rotineiramente pelos envolvidos no processo.

Os praticantes da dialética e da retórica abordam temas cruciais para a vida coletiva, e a sua atuação é decisiva em situações ainda não marcadas por definições finais, categóricas.

Se for aceitável a tese que situa a teorização de Dewey nas cercanias das artes argumentativas, torna-se interessante assinalar que algo semelhante encontra-se em Democracia e educação, obra que define a comunicação como fenômeno vital para a coletividade. Nesse livro, Dewey (1959, p. 4) diz que a "sociedade não só continua a existir pela transmissão, pela 


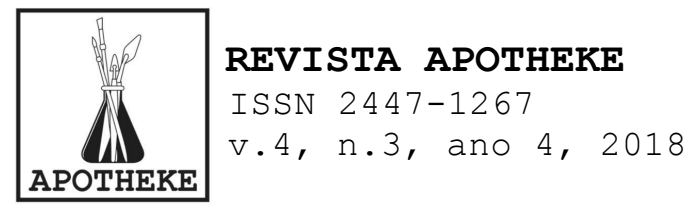

comunicação, como também se pode perfeitamente dizer que ela é transmissão e é comunicação"; e acrescenta que a educação "consiste primariamente na transmissão por meio da comunicação" Dewey (idem, p. 10). A simples articulação lógica dessas duas premissas permite perceber que uma sociedade não pode existir, como tal, sem que se instituam processos educacionais efetivos.

Dewey (1959, p. 207) explica que, para alcançar os objetivos socializadores que se espera da comunicação, é preciso que os conteúdos transmitidos tenham conexão íntima com a experiência do aprendiz; caso contrário, as palavras que se empregam não passarão de "puros estímulos sensoriais, desprovidos de significação". Educar efetivamente, portanto, consiste em estabelecer formas de comunicação essencialmente baseadas na experiência do aluno. Para elaborar essas formas ou métodos educacionais, Dewey (idem, p. 6) considera necessário conhecer a experiência das pessoas a quem se pretende educar, ainda que para isso seja preciso contar somente com a imaginação.

Após enunciar essa ideia, o filósofo introduz uma frase enigmática: "Toda comunicação é semelhante à arte". Digo enigmática porque essa frase não possui, naquele contexto discursivo, nenhum apelo argumentativo, nada acrescentando ao que acaba de ser dito, nem ao que é dito em seguida, quando Dewey (1959, p. 6) afirma que toda prática social compartilhada é educativa para os que dela participam.

Investigando o modo como Dewey emprega a palavra arte em Democracia e educação, é possível concluir que a comunicação é semelhante à arte porque os dois conceitos designam "atividades socializadoras que envolvem a totalidade emocional e intelectual de seus participantes, ultrapassando o âmbito meramente individual" (Cunha, 2005, p. 15). Assim, podemos 
dizer que toda prática social compartilhada é educativa quando a comunicação entre quem ensina e quem aprende coloca em primeiro plano a experiência do educando, tal como ocorre nas artes argumentativas.

\section{A radicalidade da educação como arte}

As considerações feitas por Dewey em Arte como experiência podem suscitar em nós o desejo por formas de educação mais inventivas, mais humanizadoras, distanciadas do modo como vêm sendo tratadas as problemáticas educacionais na atualidade. As reflexões do filósofo podem nos levar a perceber que as nossas práticas educativas precisam ser guiadas menos por resultados, menos por práticas mercadológicas que privilegiam os resultados, como se a educação fosse um simples contrato entre vendedores e compradores, e mais pela satisfação inerente ao processo de educar.

A filosofia estética deweyana ensina que a arte não se traduz em estatísticas e que as relações humanas podem ir além de regras fixas e estatutos administrativos (Dewey, 2010, p. 585). E assim, por analogia, podemos nos sentir livres para acreditar que a educação pode ser diferente do que é hoje, porque as ações pedagógicas não acontecem no campo do necessário, mas no terreno da contingência, espaço em que as deliberações morais são passíveis de alteração mediante o debate honesto e aberto acerca de nossas aspirações e emoções mais profundas. No livro Human nature and conduct, Dewey (1922, p. 137) diz que "precisamos de mais 'paixões', não menos". Parafraseando o filósofo, podemos então dizer que, na educação, precisamos de mais arte, não menos.

Arte como experiência não é uma obra sobre educação, mas em suas páginas finais Dewey (2010, p. 581-582) nos incentiva 
a refletir sobre tais assuntos, ao comentar que, pela comunicação, a arte pode vir a ser um valioso instrumento da instrução, e que nós só não nos aventuramos a pensar nesses termos porque estamos habituados a ver o ensino e a arte como domínios completamente isolados. Dewey nos motiva a nos revoltarmos contra as formas de educação que deixam de lado a imaginação, os desejos e as emoções, e transformam a relação educativa em algo estável, quantificável, frio.

A transposição das reflexões deweyanas para a esfera da educação requer, no entanto, certo cuidado, para que não sejamos tentados a aprisionar as teses do filósofo no interior de um "registro meramente didático", como bem alerta Pedro Pagni (2011, p. 43), referindo-se ao modo como Dewey foi apropriado pelos educadores, não só no Brasil como em outros países. É preciso destacar que a discussão feita por Dewey (2010, p. 551) em Arte como experiência enfatiza o caráter social da experiência estética, ao dizer que essa experiência representa "uma manifestação, um registro e uma celebração da vida de uma civilização", bem como uma maneira de "promover seu desenvolvimento, e também o juízo supremo sobre a qualidade dessa civilização".

As temáticas sociais e políticas têm posição fundante na filosofia deweyana. No livro Democracia e educação, lemos que a expressão sociedade democrática diz respeito ao estabelecimento de relações mútuas entre as pessoas, por intermédio das quais é possível reconstruir hábitos e instituições sociais. Na democracia, os objetivos das ações humanas - e Dewey (2007, p. 11-12) menciona particularmente os objetivos educacionais - são intrínsecos aos processos de produção; quando os fins não advêm do "livre desenvolvimento das próprias experiências", sendo impostos por alguma 


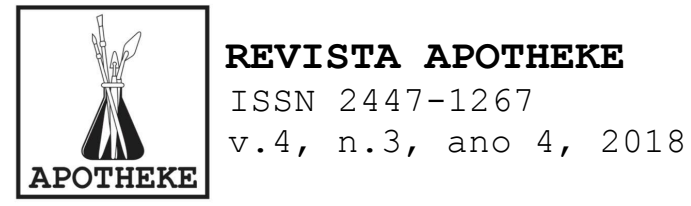

autoridade externa, é sinal de que as relações sociais estão em desequilíbrio.

Nesse livro, Dewey (2007, p. 74) também discorre sobre os fatores que impedem a realização da democracia e da educação democrática, identificando o cerne do problema na "divisão da sociedade em classes ou grupos mais ou menos rigidamente separados". Tal divisão é o que ocasiona as formulações dualistas, como "trabalho e lazer, atividade prática e atividade intelectual, homem e natureza, individualidade e associação, cultura e vocação", o que, por sua vez, inviabiliza o compartilhamento de experiências, atividades e interesses entre os indivíduos das diversas classes (idem, p. 31). Por trás das elaboradas distinções intelectuais e abstratas oriundas de teorias filosóficas e pedagógicas, habita a profunda "distinção social entre os que procuram se envolver com um mínimo de pensamento autônomo e apreciação estética e os que se preocupam mais diretamente com as coisas da inteligência e com o controle da atividade dos outros" (idem, p. 36-37).

Em Arte como experiência, o filósofo desenvolve raciocínio semelhante, dizendo que os isolamentos observados no campo estético - entre as condições de produção do objeto artístico e o objeto em si mesmo, bem como entre o produtor e - receptor da obra de arte - revelam um traço característico da sociedade contemporânea: "o abismo que costuma existir entre o produtor e o consumidor", situação que cria "um abismo entre a experiência comum e a experiência estética" (Dewey, 2010, p. 69). Nesse livro, a avaliação dos fatores responsáveis pelos dualismos da vida contemporânea é ainda mais contundente do que em Democracia e educação:

o crescimento do capitalismo foi uma influência poderosa no desenvolvimento do museu como o lar adequado para as 


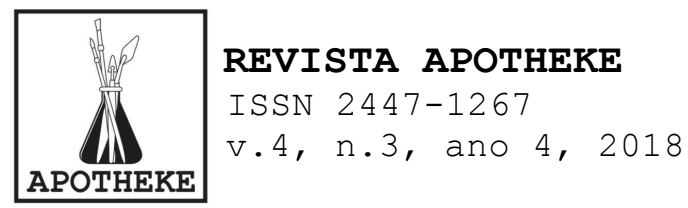

\begin{abstract}
obras de arte, assim como na promoção da ideia de que elas são separadas da vida comum. Os novos-ricos, que são um importante subproduto do sistema capitalista, sentiram-se especialmente comprometidos a se cercar de obras de arte que, por serem raras, eram também dispendiosas. Em linhas gerais, o colecionador típico é - capitalista típico. Para comprovar sua boa posição no campo da cultura superior, ele acumula quadros, estátuas e joias artísticos do mesmo modo que suas ações e seus títulos atestam sua posição no mundo econômico. (Dewey, 2010 , p. 67)
\end{abstract}

Segundo Dewey (2010, p. 576), o cerne do problema reside no âmbito da produção, e não haverá solução verdadeira para o cenário contemporâneo antes que aconteça uma "alteração social radical, que afete o grau e o tipo de participação do trabalhador na produção e na administração dos bens que ele produz"; somente mudanças assim profundas poderão alterar "o conteúdo da experiência em que entra a criação dos objetos feitos para uso". Dewey acredita que saídas paliativas, como o aumento das horas de lazer, por exemplo, servem somente para preservar a "divisão dualista entre trabalho e lazer", pois o que realmente impede que o trabalhador tenha interesse naquilo que faz - "pré-requisito essencial da satisfação estética" - é - "controle oligárquico dos processos e produtos do trabalho". Enquanto a arte for o salão de beleza da civilização, nem a arte nem a civilização estarão seguras. (Dewey, 2010, p. 577)

\footnotetext{
(..) a própria arte não estará segura, nas condições modernas, enquanto a massa de homens e mulheres que faz - trabalho útil do mundo não tiver a oportunidade de ficar livre para conduzir os processos de produção, e não for ricamente dotada da possibilidade de gozar dos frutos do trabalho coletivo. (Dewey, 2010, p. 577-578)
}

Há várias maneiras de nos apropriarmos da estética deweyana no terreno da educação, e todas elas podem render bons frutos. Dewey nos inspira a introduzir as artes na prática educativa e a criar novos métodos para o ensino da 
arte; e também nos inspira a fazer da educação uma experiência gratificante e humanizadora. Resta saber se ele ficaria plenamente satisfeito com essas medidas ou se, mesmo concordando com elas, não nos alertaria para a necessidade de enxergar além da escola, para que não sejamos responsáveis pela invenção de novos dualismos. Talvez Dewey considerasse paliativas as nossas soluções e nos pedisse para examinar mais detidamente a radicalidade política contida na proposta de tornar a educação uma arte.

\section{Referências}

ANDRADE, Erika Natacha Fernandes; CUNHA, Marcus Vinicius (2012). Concordâncias e discordâncias de Dewey com Freud. Educar em Revista, Curitiba, v. 44, n. 2, p. 275-291, abr./jun..

BARBOSA, Ana Mae (1982). Recorte e colagem: influências de John Dewey no ensino da arte no Brasil. São Paulo: Autores Associados/Cortez.

BARBOSA, Ana Mae (2002). John Dewey e o ensino da arte no Brasil. 5. ed. São Paulo: Cortez.

BARBosA, Ana Mae (2003) Arte Educação no Brasil: do modernismo ao pósmodernismo. Arte, São Paulo, n. 0, out.

BERTI, Enrico (1997). Aristóteles no século xx. São Paulo: Loyola. Tradução de Dion Davi Macedo.

CRICK, Nathanael (2010). Democracy and rhetoric: John Dewey on the arts of becoming. Columbia: University of South Carolina.

CUNHA, Marcus Vinicius (1994). John Dewey: uma filosofia para educadores em sala de aula. Petrópolis: Vozes.

CUNHA, Marcus Vinicius (2001). John Dewey: a utopia democrática. Rio de Janeiro: DP\&A.

CUNHA, Marcus Vinicius (2005). Comunicação e arte, ou a arte da comunicação, em John Dewey. Revista Brasileira de Estudos Pedagógicos, Brasília, v. 86, n. 213/214, p. 9-20, maio/dez.

CUNHA, Marcus Vinicius (2010). História da educação e retórica: ethos e pathos como meios de prova. In: Silva, M.; Valdemarin, V. T. (Org.). Pesquisa em educação: métodos e modos de fazer. São Paulo: Cultura Acadêmica.

CUNHA, Marcus Vinicius; GARCIA, Débora Cristina (2011). Pragmatism in Brazil: John Dewey and education. In: PAPPAS, G. F. (Org.). Pragmatism in the Americas. New York: Fordham University. 


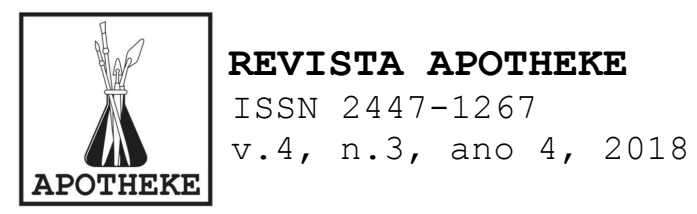

DEWEY, John (1922). Human nature and conduct: an introduction to Social Psychology. The Middle Works of John Dewey, 1899-1924. Volume 14.

DEWEY, John (1959). Democracia e educação: introdução à filosofia da educação. 3. edição. São Paulo: Nacional. Tradução de Godofredo Rangel e Anísio Teixeira.

DEWEY, John (2007). Democracia e educação: capítulos essenciais. São Paulo: Ática. Tradução de Roberto Cavallari Filho.

DEWEY, John (2010). Arte como experiência. São Paulo: Martins Fontes. Tradução de Vera Ribeiro.

MEYER, Michel (2007). A retórica. São Paulo: Ática. Tradução de Marly N. Peres.

MOREIRA, Carlos O. Fiúza (2002). Entre o indivíduo e a sociedade: um estudo da filosofia da educação de John Dewey. Bragança Paulista: EDUSF.

PAGNI, Pedro Angelo (2011). Leituras sobre as contribuições de John Dewey para a educação. In FÁVERO, A. A.; TONIETO, C. (Org.). Leituras sobre John Dewey e a educação. Campinas: Mercado de Letras.

PIMENTA DE ARAÚJO, Rita; CUNHA, Marcus Vinicius (2011). A apropriação de Aristóteles por John Dewey. Educação e Filosofia, Uberlândia, v. 25, n. 49, p. 43-70, jan./jun.

PERELMAN, Chaïm (1982). The realm of rhetoric. Notre Dame: Notre Dame University. Tradução de William Kluback.

PERELMAN, Chä̈m; OLBRECHTS-TYTECA, Lucie (1996). Tratado da argumentação: a nova retórica. São Paulo: Martins Fontes. Tradução de Maria E. Galvão.

REBOUL, Olivier (2004). Introdução à retórica. São Paulo: Martins Fontes. Tradução de Ivone Castilho Benedetti.

SOUZA, Rodrigo Augusto (2011). O lugar de pensamento de John Dewey na historiografia da educação brasileira. In FÁVERO, A. A.; TONIETO, C. (Orgs.). Leituras sobre John Dewey e a educação. Campinas: Mercado de Letras.

TOULMIN, Stephen (2001). Os usos do argumento. São Paulo: Martins Fontes. Tradução de Reinaldo Guarany.

VALDEMARIN, Vera Teresa (2010). História dos métodos e materiais de ensino: a escola nova e seus modos de uso. São Paulo: Cortez. 